\title{
The Two-Level Model of the Mathematical Training of Managers in the Advanced Training Environment
}

\author{
Elmira B. Adigamova \\ Kazan National Research Technical University named after A.N. Tupolev, 420111, Kazan, Russia \\ E-mail: frau.levina2010@yandex.ru
}

Ekaterina K. Dvoryankina

Viktor A. Kazinets

Irina A. Ledovskikh

Natalya P. Tabachuk

Nadezhda A. Shulika

Irina V. Karpova

Far Eastern State University of Humanities, 680000, Khabarovsk, Russia

\section{Doi:10.5901/mjss.2015.v6n6s2p512}

\section{Abstract}

Relevance of the article is determined by the need to create a system of advanced education by studying the need for potentially demanded features of future specialists. One of the components of advanced training is the specially organized advanced environment that enables to change fundamentally the education model. The authors have shown the need for changing the approach to training in order to ensure the transition to the formation of students' lasting creative and research skills, the ability to solve professionally oriented problems. The authors have studied the mathematical bachelor and master training in management based on the competence approach and contributing to the formation of professional competences. The author's model provides visualization, setting the structure and description of pedagogical functions in the environment of advanced training. This article is intended for teachers, researchers, heads of educational institutions involved in the training of Bachelors and Masters of Management.

Keywords: professional training, a two-level mathematical training, the students - managers, advancing training, modeling.

\section{Introduction}

\subsection{Background}

The current socio-economic conditions set realization tasks of advanced training for the higher professional education. The idea of advanced education was reflected in the scientific and educational literature (Novikov \& Zuev, 2000; Neymatov, 2002 and others)

The main idea of advancing is the understanding of the need to reduce the time lag between existing and broadcasted knowledge and their implementation in future work by students. The advanced training in modern sense is not so great "baggage" of theoretical knowledge in a particular area, as the fundamentals of the phenomena and processes, coupled with the ability to study in the dynamic conditions of the developing production and social trends. Modern information saturation, the development of engineering and technologies, obviously, increase the dynamics of transformation and updating of knowledge, and the only option of adaptation of a potential employee for future work is the development of his/her abilities and the needs for continuous learning. The ability of the professional training system to 
"work" ahead of the curve is connected with the forecasting socio, science and engineering development trends, with identification of the need for amount of specialists in each existing education area and / or creating new training profiles. However, the implementation of this concept is difficult to fit into the framework of the organization of high school professional education, reproducing the traditional (and often lagging) activity patterns, requiring typical repetition (broadcast) from students.

\subsection{Status of a problem}

One of the components of advanced training is a specially organized environment (advanced environment), which enables to change fundamentally the model of learning through the integration of "university-production", " university Research Center", " university - social partners".

In the most general sense the developing educational environment is any socio-cultural space in which, spontaneously or with varying degree of organization, the process of human development is realizing. From the standpoint of the psychological context, according to L. S. Vygotsky (1984), L. V. Zankov (1975), A. N. Leontiev (2001), D. B. Elkonin (1989) and others, developing environment - this is an educational environment, ordered in a certain way, in which it is realizing the developing education, providing "complex opportunities for development of all subjects of the educational process" (Yasvin, 1997).

Thus, L. V. Lidak and E. V. Gushina (2009), studying developing educational environment of university as the factor of student's self-development dynamics, indicate that:

- the educational environment of university is an important additional resource for personal development and self-realization of the student;

- the structure of developing educational environment is heterogeneous and consists of subject-material, research, educational, informational, social and communicative components that directly or indirectly affect the identity of the student;

- $\quad$ the psychological support of the educational environment use for personal development and self-realization of students is a complex of measures for psychological study, consultation and correction of educational process, enhancing the effectiveness of training activities and professional orientation (Timofeev, 2009).

\subsection{The research hypothesis}

From our position, the advanced environment is a set of organizational and pedagogical conditions, forms, methods and means of education, that is, scientific-methodical, training and personnel providing of educational activities of students oriented on changing the structure of knowledge. In this aspect, we consider the use of the principle of "advanced training" (Zankov system, 1975), designed for a school education) reasonable, it implements an intensive personal development by creating learning conditions at a high level of complexity by using interdisciplinary connections, when the subject of study is developing independently and reasonably taking into account the personal characteristics. These university pedagogical conditions should be combined with the organizational terms of professional training, thereby forming the necessary competences in accordance with the FSES.

\section{Materials and Methods}

\subsection{Methods of the research}

During the study were used the following methods: analysis of normative documents and activity products, content analysis, a method of thought experiment, modeling, forecasting, systematization and summarizing facts and concepts, projection, a method of expert evaluations, analysis of students' performance, study and generalization of mathematical training experience of managers.

\subsection{Methodological approaches of the research}

The leading research approaches are the competence and person-centered as a certain ideology and a set of solution methods. In practice, the competence approach is the reaction of professional education to the changing social and economic conditions, the processes appeared along with the market economy (Gilmeeva, 2002; Mukhametzyanova, 2012; Zimnaya, 2004). The essence of the competence approach, evident in the normative documents and scientific 
publications, involves the formation of competences as a result of the practical orientation of the educational process, including the ability to cope with the tasks of their professional field. Competence approach expands and complements the classical academic approach in education, it is aimed at the development of students' competences, which are in demand on the modern job market and provide the experience of independent activity. In this approach knowledge and skills are the foundation for competences.

Of course, high-quality mathematical training of the future managers and economists is possible only when the individual character of each student learning is considered. This fact enables to take into account the person-centered approach, the essence of which is in training centered on student's abilities, their opportunities and features.

The means of implementation of the person-centered approach (Bondarevskaya, 1997; llyasov, 1986; Shishov, 1990) to the mathematical training of future managers and economists may be the construction of the individual educational trajectories in mathematical disciplines through the use of different levels of complexity of individual tasks, relevant to student's abilities and opportunities, conducted under the teacher's coordination and consulting.

\subsection{Peculiarities of mathematical training in advanced environment of a research university}

For the manager, getting education in a research university, mathematical training should not only serve as a course of "general development", but to be like the vitally necessary knowledge, defining the main aspects of the future practice. If in the course of the educational process a future manager has got the right idea of what mathematics is, what is the mathematical approach to the study of aspects of their professional activities, how it should be used and what it can give, has acquired a solid foundation of mathematical knowledge and the necessary mathematical culture, has developed the ability to think independently, then, having knowledge of the basic concepts and mathematical disciplines, he/she will easily acquire the required additional knowledge.

The peculiarity of the mathematical training of managers in this case is considered that mathematics, firstly, a comprehensive science discipline, and, secondly, has a professionally oriented potential, determined by application of mathematical methods as a means of research, forecasting and design processes in various sectors of the economy. The mathematical training of students in economics is designed to provide them by training, that is necessary to form such mathematical knowledge and skills that will be useful in the future to study professionally focused disciplines for performing projects, for professional activity in general and continuing education (Master's degree, postgraduate and doctorate). Namely the mathematical training occupies a leading position in shaping the science-research thinking. Transition to the advanced training requires the implementation of training techniques, correlating with the formation of specific competences in a specific professional sphere, shifting the emphasis on the problematic, productive and search training with the personal qualities and abilities of the student. Considering the advanced environment of the research university in the context of mathematical training of managers, it is obvious that you need to change the approach of training by providing a transition to the formation of students' creative and persistent research skills, ability to solve professionally oriented problems. Overcoming the isolation of training modules and disciplines themselves, the implementation of multi-disciplinary research, the understanding of the need for research practices in business today (when every significant management decision can be regarded as an experiment) and the existing scientific and methodical base define implementation ways of the mathematical preparation of bachelors, forms and methods of training process and science-research activities.

\section{Result}

\subsection{Factors of successful development of the mathematical training of future managers}

Factors, representing the role of students' learning activity, influence mathematical training; student's activity; motivation of educational activity; the ability of students to educational activity.

The level of students' activity defines their role in the training process, the tendency of students' transformation, awareness of perception, intention to creative cognition. Methods for activity increasing are based on changes in organizational forms and means of training activities, implementing of innovative forms of learning process (discussions, debates, evaluation of other students, search and problem methods).

Description of motivational sphere is traditionally represented by a set of goals, needs, interests and motives (Markov, 1990), which become the basis of the discipline learning, thereby forming an interest in the discipline in terms of the interest of the practical significance and awareness of the personal need for achievements. The sequence of goals of mathematical disciplines learning in the condition of motives recognition determines the stages of training and means of 
competence formation in the mathematical training of managers.

Needs for training, new knowledge acquisition are determined by objectives and goals of the student, his/her ambitions, and thus form individually a chain of human values, creating a basis for his/her action, awakening activity. Need for cognition are determined through the personal interest in some learning activity through a positive attitude toward studying and learning tasks. Development of learning abilities is the condition of the modern educational system that meets the requirements of socio-economic and technological development of society. Fast learning, continuous self improvement is one of the requirements of employers to the profession of a manager.

From our point of view, the development of modern mathematical training aimed at the full use of mathematical knowledge in the professional field and the development of thinking and knowledge of the student can be built on the basis of an integrated set of knowledge and skills of multidimensional disciplines studied throughout the university education.

\subsection{Principles of organization of the advanced environment in terms of a research university}

In the context of national research universities, designed to implement innovative and productive ways of training graduates for high-tech economic industries, organization of the advanced learning environment is associated with the implementation of the principles:

- integration of science, industry and education;

- development of science activities involving teachers, bachelors, masters and PhD students of the national research university;

- continuous training of teaching staff;

- providing management of innovative training.

These principles are realized through: the organization of the material and technical base, providing conditions of professional and personal development for each student - the learning environment, including information and software training; creating a system of training and retraining, including internships, further training, master's programme, postgraduate and doctoral studies, attraction young scientists to the teaching activities in accordance with the cycle of the implementation of the research activities; developing instructional training systems for all levels of learners, including the formation of professional educational programs and research competences, innovative methods of knowledge transfer for the implementation of the advanced training principles; organization of the system of educational activities management, including the management of training quality, management of training, upbringing and development of students in the advanced environment, strategic planning and development of activities.

\subsection{The model of two-level mathematical training of managers in terms of a research university}

The mathematical training of bachelors of management, based on the competence approach and meeting the requirements of FSES, should be considered in the same block as the training on mathematical disciplines (higher mathematics, probability theory and mathematical statistics, methods of managerial decision- making) and on the related disciplines ("Information Technologies in Management" ,"Statistics", "Methods of managerial decision-making", "Game Theory").

To describe the didactic process of two-level mathematical training of managers authors have developed the model that provides the visualization, setting the structure and description of pedagogical functions in terms of a research university (Fig.1).

The model, describing the process of a two-level mathematical training, is a system of formation of professional competence by specially organized, controlled by collaborative activity of problem-search, research character of the teacher and the student. Organization of a didactic process of two-level mathematical training of managers is based on competence and personality-oriented approaches considering the principles of: scientificity; unity of fundamental and professionally-oriented mathematical content of training; module character; individualization; problematicity; integrity.

Implementation of mathematical training includes a set of forms, methods and tools aimed at the formation of professional competences of managers in learning disciplines of mathematical cycle, while the emphasis is not on "mathematics education" but education "with the help of mathematics", aimed at the general cultural and intelligence development of a person basing on the interests, aptitudes and abilities of the student.

Our proposed technique of mathematical training of managers is based on the following items, providing the necessary specificity of formation and realization of a two-level mathematical training of managers:

- "Fixed point" - mathematization of all areas of science is considered as infrastructure ("Fixed point"), where 
you can build a variety of engineering, technological, economic, scientific and social projects. Mathematics and logic apparatus is the basis of all disciplines and originating as practical knowledge about objects and phenomena, in the process of defining regularities, interconnections there develop the mathematical apparatus;

- Versatility - supports the universality of mathematical methods that are used in virtually all spheres of activity, for example, methods of mathematical modeling and mathematical statistics;

- Applied importance ensures the unity of the fundamental mathematical knowledge and the existence of the universal apparatus for the professional work of a manager;

- $\quad$ "The core and cover" - compose the unity and carry the same amount of information on the phenomenon. The stable core of a system is a collection of completed, that is sensible and easily reproducible, discipline knowledge; the cover system is an area of application of this knowledge in solving new problems so it is going on an evolution of the core.

"Chain Reaction" - when the required level of knowledge is achieved the positive return and direct interdisciplinary links begin to operate at full capacity, so a new process of forming a knowledge base occurs.

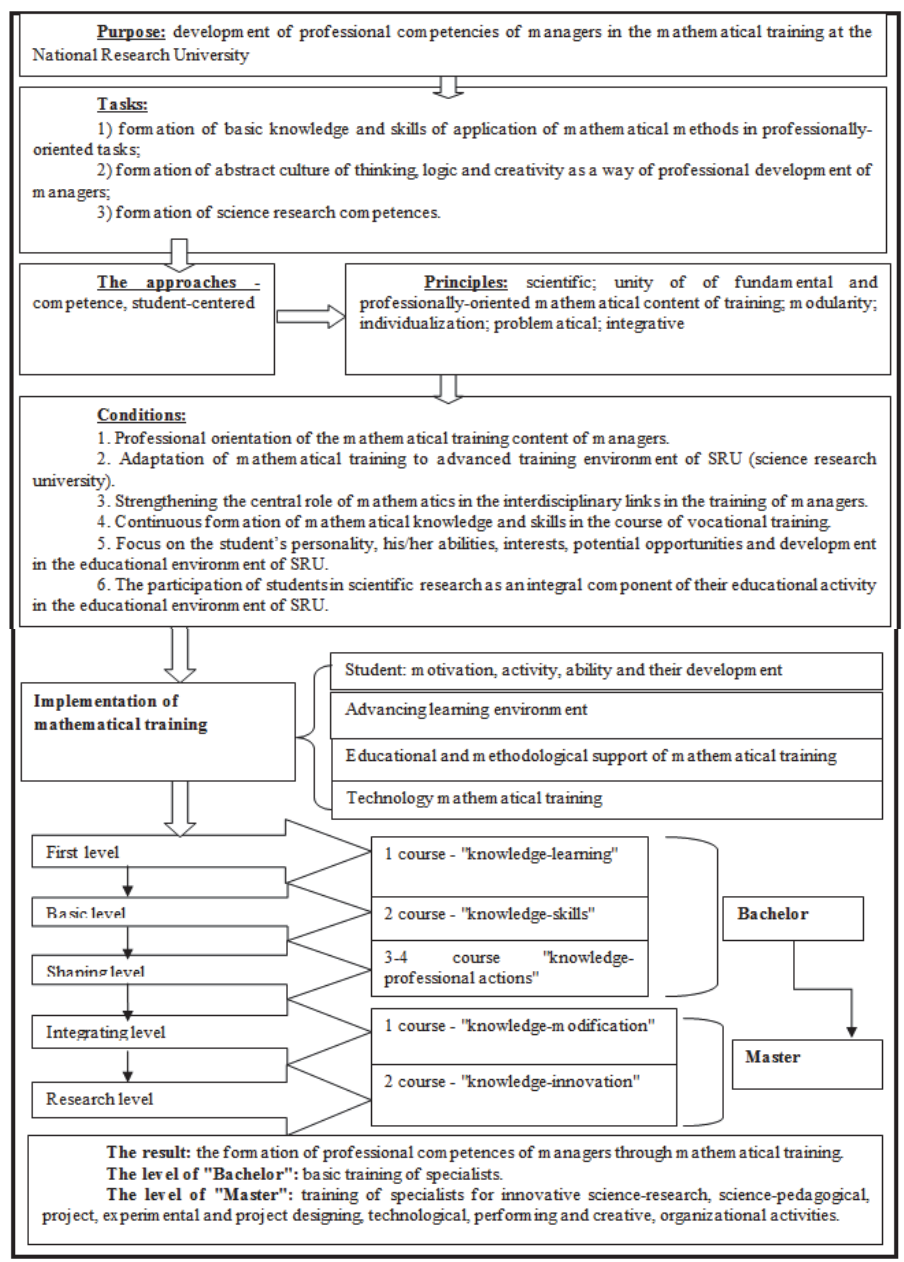

Figure 1. The model of a didactic process of two-level mathematical training of managers 
Freedom in course correction of mathematical cycle disciplines is very low - on the one hand, strong requirements of FSES and the need for an individual approach to learning, from the other, make a profound contradiction in solving methodical problems of teaching mathematics. The second contradiction of the manager's mathematical competence formation problem is that while teaching students to independent thinking, to non-standard problems creative solutions, it is easy to overlook the basic foundations of the course (for example, applied mathematical programs easily solve the standard math problems, giving a ready answer).

Introduction to the learning process not a descriptive material but problems which involve knowledge search to find the answer, starting with the definition and finishing with the solution method, can act as a way of forming the necessary mathematical knowledge and competences, ensuring the development of students' productive, creative thinking and abilities to continuous learning.

In this study, as the best ones, we have selected and implemented the tasking technique of education, which includes the formation of the knowledge base of students in learning disciplines of mathematical cycle. During the implementation of the disciplines of mathematical cycle in each training course it is usually set the aim to ensure appropriate teaching materials, where the specific role is devoted to different types of professionally oriented problems:

1) 1 course - "knowledge-learning" (initial level, bachelor). The essence of this phase is to determine the properties of usefulness of studying processes and phenomena important for his/her activities, establishing links between the available and newly acquired knowledge and skills.

2) 2 course - "knowledge-skills" (basic level, bachelor). It is clear that information knowledge is useless without the understanding and application to an action, and skills without knowledge provide only automatic execution of actions. The set of "knowledge-skills" makes it possible to adapt to any training or work situation, to analyze the performance, to understand the processes essence. That is the essence of this stage is in the acquisition of skills to work with the assimilated knowledge, to use them in a practical and independent work.

3) 3-4 course "knowledge- professional actions" (formative level, bachelor). This provision (knowledge-action) suggests that the assimilated information, acquired ways of its application is the state of the student's personality, the driving force of his/her actions. This provision is developing in the theory of the stage formation of mental actions (Galperin, 1969), replacing the "black box" by deliberate action formation in any sphere of activity. Professionally meaningful, reasonable steps can be realized only at a certain level of intellectual development, existence of discipline knowledge and basic skills.

4) 1 course - "knowledge-modification" (integrating level, Master). At this stage, it is going the integration and systematization of knowledge from different subject areas to the professional activity, "systematization of concepts into the knowledge system" (Nonaka, Takeuchi, 2011); actualization, increasing and dissemination those knowledge, basing on which it will be carried out professional activity; transformation of professional competences complex into the professional competency.

5) 2 Course - "knowledge-innovation" (research level, Master) - the generation of new knowledge, the dynamic development of knowledge, the transformation of subject knowledge into professional products or techniques. This type of knowledge refers to strategic resources, key success factors, enabling to provide innovative development of society as a whole.

The advantage of the tasking technique of mathematical training is an oriented development of abilities (including the individual) to the training and development that is the determining factor of the competitive specialist in modern conditions.

The academic and methodic software of two-level mathematical training is a necessary condition for its implementation in the advanced environment. In general, the academic and methodic software is a complex of educational and methodical documentation for organization of training activities in any discipline.

Educational and methodological support of the two-level training of managers includes:

- The concept of two-level mathematical training - key prerequisites and tasks of professional activity of graduates (bachelor and master), which describes the gradual formation of professional competences in the mathematical training of bachelors and masters;

- The curriculum with a reflection of the disciplines studying graph of mathematical training during the whole education of Bachelors and Masters in Management;

Work programs of disciplines of mathematical training;

The program (direction) of science-research students' work in the professional field using mathematical tools;

Teaching aids, including the collections of problems, the electronic version of lectures and other resources;

Test materials: tests, examination questions and etc.

Guidelines for the organization of independent work of students, providing technological effectiveness of training. 
The resultative block of this model determines the efficiency of formation of professional competences during the two-level mathematical training and is characterized by distinguished indicators of professional competences performance in future career of Bachelors and Masters in Management.

\section{Discussions}

Modern development trends in social and economic relations confirm the emergence of new needs. Many professional activities require a change in approach to the organization and the training methodic of competitive specialists. Mathematics, as the logical basis of all sciences, is under a careful attention of scientists educators ((Jurbenko, 1998 and others), the basis of mathematical training of future managers are widely covered in the educational research (Kulnevich,1998; Stepanov,2003), however, the problem of organizing a two-level mathematical training of future managers in terms of a research university is not reflected in recent studies.

\section{Conclusions}

The graduate of a research university in a professional situation should be capable to a system action, which involves the analysis, design and implementation in an uncertain environment, and, therefore, requires creativity, quick thinking and decision-making. An important consideration in the organization of the mathematical training of future managers in a research university is the development of a specific program of its realization in accordance with modern requirements: the changes in the disciplines' content of the mathematical cycle, the organization of students' work within self-study hours, the organization of certain competitions at university, students' specialized publications and websites, projects and others. For this system it is reasonable to develop and implement the author's two-level model of future managers training.

\section{Acknowledgments}

The authors thank all participants of this study for their kind cooperation.

\section{References}

Bondarevskaya, E. V. (1997). Humanistic paradigm of personality-oriented education. Pedagogy, 4, 18-25.

El'konin, D. B. (1989). Mental development in children. Moscow.

Galperin, P. Y. (1969). To study the intellectual development of the child. Questions of psychology, 1, 79-83.

Gilmeeva, R. H. (2002). Development of professional competence of teachers in the training. Moscow. Publisher Methodist.

Ikudzhiro Nonaka, Hirotaka Takeuchi (2011). Company creator of knowledge. The birth and development of innovations in Japanese firms. Olympus-Business.

Ilyasov, I. I. (1986). The structure of the learning process. Moscow. Russian Pedagogical Society Press.

Jurbenko, L. N. (1998). New technologies in teaching the exact sciences. Kazan. Kazan Education Publisher.

Kulnevich, S. V. (1998). Management of professional self-determination. Moscow. Studies grant press.

Leontiev, D. A. (2001). Professional self-determination as the construction of images of possible future text. Questions of psychology, 1, $57-65$.

Lidak, L.V. \& Gushina, E. V. (2009). Develop educational environment of high school as the factor of self-realization of the dynamics of the student. Moscow. Notes scientists.

Markov, A. K. (1990). Formation of motivation of the doctrine. Moscow. Education.

Mukhametzyanova, F. S. (2012). The innovative principles in the preparation of teachers of vocational training. Kazan pedagogical journal, 4(1), 186-190.

Neymatov, J. M. (2002). Education in the twenty-first century. Trends and prognozy Algorithm Press.

Novikov, P. M. \& Zuev, V. M. (2009). Advanced professional education. Moscow. Scientific and practical guide Press.

Shadrikov, V. D. (1993). The philosophy of education and educational policy. Moscow. Press Education.

Shishov, S.E. (1990). Concept of competence in the context of the quality of education. Standards and monitoring in education, 2, 132.

Stepanov, E. N. (2003). Student-centered approach to teaching activities. Scope of the shopping center, 126

Timofeev, Y. F. (2009). Systems hike in the organization of the educational environment as the basis for creative activity in the period of training of young specialists. Innovations in education, 10,103.

Vygotsky, L. S. (1984). The development of higher mental functions. Moscow journal, 156.

Yasvin, V. A. (1997).Education Week: from modeling to design. Moscow journal, 97.

Zankov, L. V. (1975). Training and development. Moscow. Russian Pedagogical Society Press.

Zimnaya, I. A. (2004). Educational psychology, Textbook for universities. Logos Press. 